\title{
The Merged Department Experience at the University of Illinois: Is there Strength in Numbers?
}

\author{
M.A.L. Smith
}

\begin{abstract}
Summary. Soils, entomology, forestry and horticulture faculty were combined into a single merged Department of Natural Resources and Environmental Sciences (NRES) during a recent College of Agriculture, Consumer, and Environmental Sciences restructuring process at the University of Illinois. The merger initially spawned multiple concerns from faculty, but after an adjustment period, ultimately resulted in enhanced organization, accountability, and collaboration. New, multidisciplinary initiatives within NRES, such as the Illinois Green Industry Survey or development of a highly successful off-campus masters program, attest to the fact that the merger brought new strength and expanded opportunities to our unit.
\end{abstract}

I n August 1995, an extensive restructuring of the College of Agriculture at the University of Illinois reduced the number of departments from 15 to 7 , with the objectives of consolidating administrative units, enhancing opportunities for faculty collaboration, and making more efficient use of staff and resources. The name of the college also changed to the College of Agricultural, Consumer and Environmental Sciences (ACES). The official reorganization underscored the college's plan to infuse new directions and fresh insights into longstanding, traditionally strong programs.

Reorganization was the result of a directed process, which began three years earlier with a strategic planning (STRATCOM) committee. This faculty team began the process of recasting the college structure. Detailed plans from the team were next evaluated by the college's executive committee, who took the charge of restructuring ACES to meet the challenges of the next century. Individual units, advisory groups, external and industry groups, and alumni were all brought into the planning process. Finally, transition teams were selected by faculty in each of the proposed new departments. These teams coordinated plans for the units ranging from administrative organization and space to curricular issues. This transition was a well-orchestrated, careful process that offered the chance for maximum faculty involvement.

\footnotetext{
Department of Natural Resources and Environmental Sciences, University of Illinois, Urbana, Illinois, 61801.

The cost of publishing this paper was defrayed in part by the payment of page charges. Under postal regulations, this paper therefore must be hereby marked advertisement solely to indicate this fact.
} 
In most cases, college reorganization brought together academic units that seemed to have a natural fit together. For example, foods and human nutrition merged with food science to create a new Department of Food Science and Human Nutrition; agriculture communications joined agriculture education and human development and family studies faculty under the new umbrella of the Department of Human and Community Development (Sheppard, 1995). For a handful of remaining departments, however, the congruity was less obvious. Horticulture was absorbed into an eclectic new Department of Natural Resources and Environmental Sciences, that (at the time of the merger) also included agricultural entomology, soil science, forestry and fiber science. Soon afterward, NRES brought in new emphases in wildlife, aquatic systems, and natural resources by partnering with the Natural History Survey faculty, and also integrated a core of faculty with expertise in sociology. To the over 50 faculty in the new departmental unit (dispersed into more than 10 different buildings on campus), it initially seemed like a potpourri-several strong and distinct themes were present; each unique and resistant to blending together.

The transition team created the following mission statement for NRES: The Department of Natural Resources and Environmental Sciences endeavors to establish and implement research and educational programs that enhance environmental stewardship in the management and use of natural, agricultural, and urban systems in a socially-responsible manner. This broad-sweeping mission statement certainly managed to envelop the traditional and longstanding mission of the former Department of Horticulture; still, the continuing presence of a vibrant horticulture program in the new unit was not immediately obvious even to our colleagues in different colleges on campus, much less to our constituencies throughout the state and nation.

Horticulture comprised the greatest proportion of NRES; about $40 \%$ of the faculty composition, $35 \%$ of the undergraduate students, and over $50 \%$ of the graduate students. All of the existing research and outreach programs in landscape, floriculture, turfgrass, vegetable crops, and pomology were preserved, and the original undergraduate curricula were absorbed into the new department's missions. The overall departmental curriculum provided majors in forestry, horticulture, and natural resources and environmental sciences. Within the horticulture major, special options in horticulture production and management, horticulture science, and urban forestry were offered.

Because this reorganization was the end result of several years of planning and implementation, and had integrated open forum opportunities for faculty input throughout the transition period, it was not greeted with the level of faculty resistance that has perhaps occurred at some other institutions. However, the horticulture faculty still harbored several concerns (a.k.a., fears of the unknown) during the early period after the merger. Would horticulture lose its identity? Will incoming students recognize that degrees in horticulture were still available at the University of Illinois? Will our courses in horticulture be cut back? When horticulture faculty retire, will the new department rehire in the same area of specialization, or will other priorities take precedence? Will we lose funding support overall? It is useful now, six years after the merger, to reassess the validity of these initial fears. Now, rather than speculating, we can evaluate which aspects of our previous department were lost in the merger, and categorize the gains achieved as a consequence of reorganization.

\section{What was lost?}

What actual losses were suffered by the former Department of Horticulture, once the merger took place? It is difficult to differentiate changes that were a direct result of the merger from changes that would have probably occurred anyway as a result of the natural evolution of departments in the changing university system. One obvious and immediate change, however, was a significant drop in the yearly base Hatch allocations for horticulture faculty. Within the same time frame, our college Office of Research implemented a formula system to distribute Hatch dollars logically and equitably, given the differential costs associated in doing research in animal sciences (assigned the highest factor in the new formula) versus plant sciences (assigned a middle factor) and social/economic sciences (assigned the smallest factor in the formula). This new formula distribution should actually have created little change in base allocations to horticulture faculty. However, after the merger, a greater proportion of these federal funds were held back in the department and not distributed to individual faculty as had previously been the norm. In part, this decision was made to even out allocations between the faculty groups who would come together from disparate departmental homes, and in part, the change was implemented so that Hatch dollars could be used for other departmental targets of interest.

Another realized loss was in the traditionally healthy influx of new applications from prospective graduate students interested in horticulture advanced degrees. In particular, there was an obvious dip in applications from abroad, where the loss of the word horticulture in the department title apparently caused foreign applicants to simply look elsewhere. The title Natural Resources and Environmental Sciences apparently did not translate as a department with a horticulture presence. Even within the United States, a decline in graduate enrollments for a MSc or PhD with an emphasis on horticultural research or outreach was noted in the initial years after the merger. A similar drop in graduate student applicants also was noted by the former forestry faculty, for likely the same reasons.

For undergraduates, a decline in enrollments from entering high school graduates or transfer students also was evident. We heard from our alumni (now professionals in the horticulture industries throughout the state) that they had assumed the Department of Horticulture had disbanded, and so, some of them instead directed their sons and daughters to attend Southern Illinois University, which still had a visible Department of Horticulture bearing that name. Similarly, high school counselors working with students who expressed a career interest in plants did not automatically make the connection between our new departmental name and the traditional horticultural production and plant science programs. Again, the students were counseled to approach other institutions of higher learning. Even for students on campus, an initial disruption in non-majors student enrollment 
was experienced, during the period when the HORT rubric in the timetable was changed to the unfamiliar NRES.

In an effort to get the department integrated, NRES implemented a single departmental seminar series on Monday at noon. Frequently (especially early in a new semester) a single seminar presentation would be delivered in the time slot. Often (especially late in the semester, when departing graduate students were struggling to fulfill their seminar presentation requirements) the department would have two or even three concurrent sessions in adjacent rooms. MSc students were given only $25 \mathrm{~min}$ time slots so that two could present in tandem within a single session, in order to accommodate the larger numbers of students. Graduate student attendance at departmental seminars was mandatory, and all faculty were encouraged to attend. In some cases, of course, the normal lecture halls were inadequate to handle the numbers in the audience. In theory, this seminar was an excellent opportunity for our department to realize the breadth of expertise within the new merged unit, and get to know other faculty and students. There was then (and still is now) a tendency for a graduate student in plant sciences to grumble "why do I have to sit through a lecture on fish?" However, the point of the merged seminar series, as of the merged department, was to allow the participants to realize new resources and chances for collaboration, and to expand their perspectives toward subjects outside of their narrow specialties. The opportunity for expanded horizons is the advantage of being at a large university, after all.

In time, with retirements of horticulture faculty, some of the open slots were collapsed to satisfy budget reductions, and in a few cases, courses previously taught by tenure track faculty were reassigned to academic professionals. Again in this case, it is difficult to pinpoint whether these losses would have occurred even if horticulture had remained a separate entity.

\section{Fighting back}

Rather than just sit back and grumble (although some of that still occurred), the horticulture faculty made a concerted effort to gain back ground that was perceived to have slipped since the merger. Horticulture faculty partnered with soils, forestry, or other disciplines represented within NRES to prepare applications for internal state-based funding opportunities. These funding sources had a strict requirement that interdisciplinary research be featured, and after the merger, it was no problem to band together a diversity of expertise by just reaching out to colleagues with vastly different backgrounds, but within the same department.

One excellent example of a new interdisciplinary initiative within our merged faculty, spearheaded by our department head, was the banding together of several faculty with expertise in horticulture, forestry, and environmental sciences to survey the green industry in Illinois. The green industry includes all commercial entities that produce, use, or sell plant materials to enhance human environments, including landscape, greenhouse, nursery, urban forests, etc. This sector has been recently described by the USDA as the largest and fastest growing in agriculture. The need for a formal, comprehensive survey was justified because Illinois' green industry (suspected to contribute billions annually to the Illinois economy) had reached a threshold where information regarding its value, structure, and performance was critical for it to function effectively. State and municipal policy-makers were unlikely to afford this diverse industry appropriate recognition and priority status without solid documentation regarding its impact on the state's economy. The institutional structure needed to move the industry forward into a regional leadership role could not be fully developed without a clearer understanding of the industry's important players and market linkages, and, in fact, it required the cooperation of our faculty from these different disciplines in order to thoroughly assess the industry's status. A coalition of Illinois green industry associations for-

Table 1. A comparison between the green industry and traditional agriculture in the state of Illinois, based on 1999 cash receipts from farm marketing (Campbell et al., 2001).

Category

Sales (million \$)

Green industry

2,936

Corn

2,564

Soybeans

2,122

Hogs and pigs

646

Cattle and calves mally partnered with our faculty at the university to support development and multidisciplinary team of NRES facstate, and follow up inquiries. A database of green industry resources in the was created through the project. the outcomes are used in this mach reach programs, and enhanced proplanning and needs assessment prioritization in our department, allowing us to channel efforts expeditiously, and weigh staffing decisions in future. This effort also served as a our ink, and further bolstered our support

Hand in hand with the above initiative, NRES hosted three separate Green Industry Summits. Partnering with industry, the first summit was a large nursery in the Chicago huge green industry presence in the metropolitan area). Later summits were in southern Illinois and in westfeculty and administration to sit and industry face to face were invaluable. Industry feedback in the curriculum, the needs for internship requirements for our undergraduates, and other issues provided a framework which shape the long range planning

In the state of Illinois, traditionally dominated by corn (Zea mays) and soybean (Glycine max) production cerns, the results of the survey pro(2) about the economic importance of the green industry. Preliminary estimates administration of the survey. The 
for 1999 showed that the product and service sectors of Illinois' green industry generated nearly $\$ 2.9$ billion in net sales (Table 1). These sales figures actually place the green industry ahead of corn and soybean production in its economic importance to the state's economy. Another impressive discovery arising from this survey were the employment and income multipliers associated with the green industry, which are 1.52 and 2.70 , respectively. This means that for every job created within the green industry, an additional 0.52 jobs are created within the overall state economy; and for every dollar paid in green industry wages and salaries, an additional $\$ 1.7$ in wages and salaries are paid within the overall state economy (Campbell et al., 2001). The compilation of this report was facilitated by the interdisciplinary partnerships of participating faculty in NRES, and has been key to capturing the recognition that the green industry deserves in the state of Illinois. The figures further emphasize the critical role that our new merged department plays, with its research, instruction, and outreach efforts relative to the Illinois green industry.

At the same time, faculty and staff made a concerted effort to publicize our strong and continuing horticulture programs. The visibility of horticulture was enhanced on the Website; contacts with industry and alumni in the state reinforced the presence of programs, and personal contacts were made with high school counselors, especially in the Chicago area.

Many faculty took the initiative to branch out of their traditional horticulture niches, and to cooperate not only with new colleagues in NRES, but also to make new research teams across the college. The shift to interdisciplinary team research was crucial to address complex system-based problems, but also better aligned the faculty relative to funding opportunities. For example, some of our traditional vegetable crops/ pomology faculty successfully partnered with faculty in the Department of Food Science and Human Nutrition, and the Department of Animal Sciences, to pursue new research initiatives in the University of Illinois Functional Foods for Health Program. This was a natural and healthy shift in research priorities, given the shrinking support and shrinking industry in the state for these commodities. The elucidation of nutraceutical components in fruit and vegetable crops is an expanding research area. Our faculty with extensive expertise in genetic manipulation of these crops (through both traditional breeding and biotechnology) were able to partner on research designed to tailor the phytochemical profiles of targeted functional food crops.

\section{What was gained?}

The Department of Natural Resources and Environmental Sciences did, in the end, accomplish a successful and satisfactory merger as gauged by several criteria. For example, it was apparent during the first year(s) that our faculty meetings and retreats tended to remain spatially segregated; all the forestry faculty huddled in one corner, horticulture in another, a grouping of entomologists in another part of the room, etc. These invisible boundaries have effectively disappeared for current departmental gatherings. Of course, some departmental business, such as the construction of degree programs, still requires cooperation among faculty within disciplines.

The merger, and the cascade of effects that made cross-collaborations seamless both within and outside of the new merged units, definitely created scores of new partnerships for our faculty. The in-house availability of sociologists and environmental scientists has proven invaluable just in the most recent years, as we face new public resistance to genetically modified organisms (GMOs) and the controversies generated by global reaction to these products. Nearly all the federal funding RFPs today emphasize the requirement for multidisciplinary, collaborative research teams.

All of the seven restructured departments in ACES suddenly had less traditional identity; this wake up call was not unique just for horticulture. So we found ourselves easily and seamlessly interacting in research (and teaching, and outreach) outside of the mold. The merger has given us access to multidisciplinary funding opportunities that would have been closed to us, had we remained isolated in our horticulture department. The truth is, in the pecking order of academia, the discipline horticulture (albeit unfairly) was never regarded by our colleagues in chemistry or even plant physiology as a place where excellent scientific work was conducted. Using the department name of Natural Resources and Environmental Sciences, alterna- tively, on a proposal application does not evoke those long-held negative stereotypes. To some extent, once faculty lost their home turf in horticulture, it became less uncomfortable to step outside of departmental boundaries altogether in the pursuit of new research funding and opportunities.

As a corollary to the research changes noted above, the Department of NRES has recently established a new off-campus master's degree program. The merged department now combines emphases in plant sciences, and the big picture view of environment and societal issues, which has been a strong draw for students (especially in the greater Chicago area) who wish to pursue continued professional development. The development of this rapidly expanding program has blended the strengths of our original programs in soils, horticulture, forestry, environmental sciences, and entomology in original and creative programs of study.

Finally, as a department, it seems that we are organized better than we were previously. In the premerger departmental model, everyone carried on business along traditional lines. Since the reorganization shook everyone out of their safety seats, the faculty is more cautiously scrutinized (by both the college and the departmental administration), and we now have significantly more accountability. We are also more carefully treading our way through new and unfamiliar territory, with a lot more forethought than before. Faculty are always thinking and reassessing how they fit into the whole structure, and what their new and unique contributions will now be. Broader value-added aspects of horticultural crops have taken priority, and the boundaries between research areas have blurred. Our opportunities have expanded since the merger; fresh challenges are welcomed by active faculty when the advantages are obvious. The new structure appears to be a better system to nurture young faculty to become citizens of the country and not just Illinois.

\section{Literature cited}

Campbell, G., T. Voigt, D. Warnock, R. Brazee, T. Endress, and J. Hall. 2001. Illinois green industry survey. Univ. Ill. Printing Serv., Urbana.

Sheppard, L. 1995. Entering a new era. Illinois Res. 37: 5-9. 